\title{
OTRAS GEOGRAFÍAS, MUCHOS MUNDOS. UN ACERCAMIENTO A LA LUCHA ZAPATISTAY LA CONFIGURACIÓN DE RELACIONES SOCIALES ANTICAPITALISTAS
}

\section{Ana Lilia Félix Pichardo ${ }^{1}$}

\begin{abstract}
Resumen: Este trabajo es parte de un proyecto de investigación en curso. Tiene el objetivo de señalar, desde las diversas disciplinas que se ha abordado al zapatismo, en qué elementos radica la peculiaridad de esta experiencia política que la diferencia de otras formas de lucha antisistémicas. El texto parte de una contextualización del levantamiento armado zapatista en 1994, así como de una breve conceptualización de las luchas antisistémicas o anticapitalistas. Posteriormente, este análisis intenta describir cómo la toma de tierra y la permanente resistencia por y en el Territorio representan la materialidad que ha dado vida a la imponente discursividad zapatista. Con esta finalidad, este artículo hace un estado del arte de investigaciones previas que, centradas en el zapatismo, abordan desde diversas disciplinas los conceptos que este trabajo intenta cruzar en el acercamiento a la experiencia zapatista. Dichos conceptos serían: discurso, autonomía, resistencia y territorio.
\end{abstract}

Palabras-clave: Zapatismo. Autonomía. Luchas anticapitalistas. Territorio. Pueblos originarios.

\section{INTRODUCCIÓN}

En la última década del siglo XX, irrumpen en el escenario político movimientos sociales que señalan, de manera categórica, que el origen de sus problemas regionales y específicos es el sistema capitalista neoliberal. El levantamiento armado del EZLN en México en 1994 es uno de los referentes más importantes de lo que Imanuel Wallerstein (2015) conceptualiza como movimientos "antisistémicos". Las protestas en Seattle en 1999, desde el interior de la gran potencia económica mundial, evidencian también un fuerte cuestionamiento de la sociedad civil hacia los procesos de globalización y sus consecuencias negativas para los intereses de la clase trabajadora. Se nomina una problemática que, desde la

1 Maestranda em Ciência Política pela Universidad Autónoma de Zacatecas (UAZ). E-mail: ana_lilia199@ hotmail.com 
naturaleza de cada movimiento, en mayor o menor medida, es expuesta como la génesis de la desposesión sufrida por los habitantes de diversos territorios.

La sociedad civil adquiere contornos específicos en organizaciones indígenas y campesinas, grupos de trabajadores de las ciudades, estudiantes y mujeres feministas, desde donde se cuestiona a los Estados y, sobre todo, se evidencia la incapacidad de éstos para responder a las demandas locales, puesto que son los intereses económicos transnacionales los que deciden sobre los territorios nacionales y sus habitantes. Es decir que, por un lado, los partidos de izquierda y organizaciones sindicales se ven rebasados por la movilización civil de quienes no ven representados sus intereses en las acciones de políticos progresistas o de líderes obreros y campesinos; por otro lado, emerge en México un movimiento armado indígena que se distancia de las prácticas vanguardistas de las guerrillas, principalmente, centroamericanas, proponiendo una forma muy particular de incidir en el escenario político. La transformación en los mecanismos de acumulación del sistema cimbra la estructura en su base social, de tal manera que los movimientos sociales no sólo no aceptan diagnósticos que no corresponden ya con las características del capitalismo, sino que, como en el caso el EZLN, llevan a cabo interpretaciones propias, con base en la experiencia de ser y vivir como desposeídos en la periferia del mundo, pero también haciendo uso de las herramientas de la teoría política.

El cambio paradigmático sobre cómo se piensa la participación política de la sociedad civil en general y de sectores anteriormente invisibilizados, en particular, es forzado por las movilizaciones, organizadas o espontáneas, de esa diversidad de grupos sociales que irrumpen en las calles con las más variadas demandas. Sin embargo, debe recalcarse la importancia de que hay categorizaciones de las problemáticas políticas y económicas que vinculan directamente la precarización de la vida de las clases bajas con el sistema de producción. El EZLN, en este sentido, desarrolla una estrategia política que parte del análisis de la realidad social y económica de México con base en la mirada hacia el sistema mundo como un rompecabezas, cuyas partes están en una relación metonímica con la totalidad. La subsunción y trascendencia que este movimiento armado hace de la tradición revolucionaria del siglo XX, desde una visión crítica, representa el punto de inflexión entre las antiguas prácticas políticas de vanguardia y las formas nuevas de ejercer la política al interior de un movimiento armado organizado.

La vitalidad organizativa del núcleo zapatista y el eco mundial que tienen sus prácticas políticas, luego de una larga resistencia contra la guerra de baja in- 
tensidad y los múltiples desencuentros entre los zapatistas y los gobiernos estatal y federal, genera múltiples cuestionamientos sobre cómo la organización militar y la toma de tierras por parte de los rebeldes han permitido el desarrollo de las nuevas formas de gobierno, como las Juntas de Buen Gobierno como vía para ejercer la autonomía; al mismo tiempo que mantienen y fortalecen lazos con la sociedad civil mexicana y organizaciones e individuos de todo el mundo. No es menor la influencia que el levantamiento armado tiene en colectivos, organizaciones e individuos que asumen los principios zapatistas expuestos en La Sexta Declaración de la Selva Lacandona ${ }^{2}$ como propios y, en torno a esa iniciativa que se declara anticapitalista, intentan construir núcleos de resistencia en el campo y la ciudad contra el despojo del capital.

La pregunta: ¿La construcción de nuevas relaciones sociales en el movimiento zapatista trascienden la lógica de acumulación capitalista y vislumbra la configuración de una geografía distinta? Exige actualizar el debate sobre la crisis del sistema y hacia dónde se dirige, pero, sobre todo, focaliza la atención en la praxis de lucha y resistencia de los movimientos indígenas, principalmente, como un detonante para la construcción de alternativas viables que permitan la sobrevivencia de la colectividad ante una guerra económica que se expande hacia todas direcciones. Particularmente, el zapatismo atrae la atención internacional por el uso de una discursividad ajena a la retórica revolucionaria de los movimientos guerrilleros de la última mitad del siglo XX; desde donde cuestiona al neoliberalismo y la crisis de los Estados Nacionales, pero también muestra cómo se deconstruye el poder, desde el ejercicio colectivo de la democracia directa, y a la supuesta totalidad hegemónica desarrollada por el capitalismo, los pueblos responden con Resistencia y Rebeldía en los distintos niveles de la vida social.

El objetivo es pensar, describir y analizar desde la negación del capitalismo, cómo se construyen relaciones sociales distintas y se reconfigura el territorio a partir de valores culturales compartidos, representando alternativas viables que trasciendan al capitalismo en su temporalidad acumulativa. Sin embargo, cabe pensar aquí al movimiento como un referente político que se articula con la sociedad civil nacional e internacional, con el objetivo de generar más núcleos de resistencia globalizada y que, así, las experiencias autonómicas puedan continuar construyendo sus formas organizativas de manera soberana. Al ser un movimiento teórico y práctico, el acudir a reflexiones de los propios zapatistas permite reconocer desde dónde surgen las diversas iniciativas propuestas a la sociedad civil y cuál es el diagnóstico que tienen del sistema capitalista como

2 Para más informaciones, ver: <http://enlacezapatista.ezln.org.mx/sdsl-es/>. Acedido en 11/05/2019. 
punto de partida para llevar a cabo los propósitos de carácter organizativo al interior de su territorio.

Estos aspectos permiten discutir qué tan conveniente es continuar hablando de centro y periferia, en un momento donde el centro geográfico no se puede pensar más ligado a un territorio nacional o si, por el contrario, sería necesario adoptar la nominación de los pueblos zapatistas - del "arriba" y "abajo"-, para referirse a la complejidad que la globalización ha impuesto en la geografía mundial con la desterritorialización del capital y los procesos de finaciarización, como elementos clave para entender las estrategias acumulativas recientes. Por lo tanto, si bien se analiza el pensamiento zapatista e iniciativas políticas en su conjunto, para comprender la transformación misma de la organización, se hace un corte temporal para analizar con mayor profundidad los últimos cinco años de actividad política del EZLN, puesto que es en este período donde se han consolidado las Juntas de Buen Gobierno como alternativas de autogobierno y autonomía, al mismo tiempo que es posible revisar su funcionamiento y la relación que ello guarda con la resistencia económica, social y cultural en contra de las relaciones de dominación que el capitalismo promueve globalizádamente.

\section{LA PALABRA COMO PUENTE}

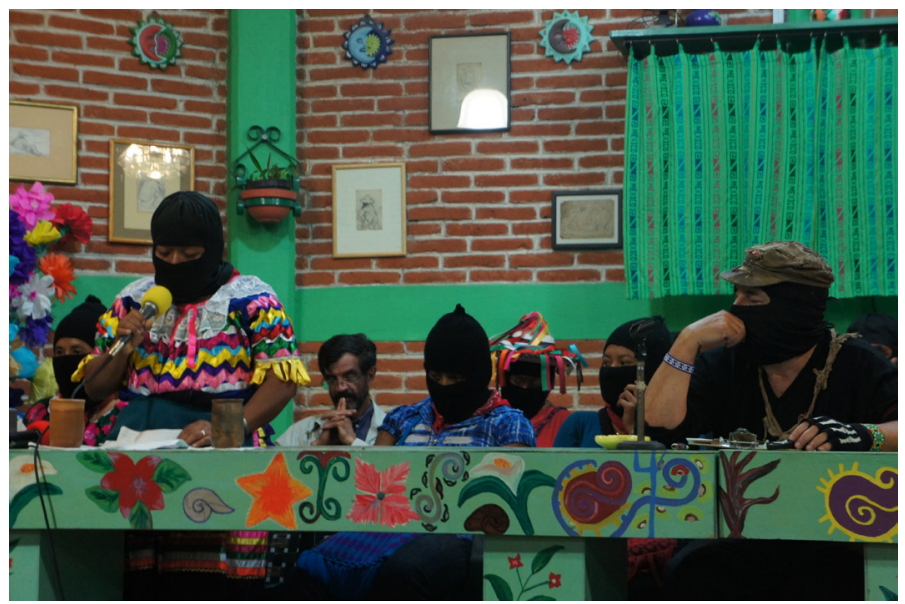

Seminario El pensamiento crítico frente a la hidra capitalista (6/05/15).

Fotografia de la autora. 
La discursividad "poética" del zapatismo condensa los cambios paradigmáticos políticos e ideológicos que diferencian al EZLN de otros múltiples movimientos insurgentes que le anteceden en México y en América Latina. Desde la toma de las cabeceras municipales en Chiapas, el movimiento explica el porqué de su levantamiento armado y comienza una fructífera comunicación con la prensa y "la sociedad civil". El uso del lenguaje representa el primer vínculo entre los zapatistas y la población nacional. Los primeros comunicados son difundidos por la prensa local y es de esta manera que se comienzan a entretejer los lazos comunicativos entre la no muy definida sociedad civil y el movimiento armado a través de su vocero y figura mediática, el Subcomandante Insurgente Marcos (hoy autonombrado Sup Galeano). La palabra de los indígenas levantados en armas, libre del dogmatismo vanguardista, acude a los símbolos revolucionarios nacionales para llamar al pueblo de México con el emblemático "Ya basta", para denunciar la marginación a que el sistema y los gobiernos los han condenado.

El lenguaje metafórico atrae la atención de los teóricos sociales, quienes realizan estudios desde las más variadas disciplinas para tratar de comprender cómo el uso novedoso de la lengua por parte del EZLN se convierte en un elemento característico del movimiento y, además, abre un puente comunicativo por el cual transitan los sectores más diversos de la sociedad civil nacional e internacional. Desde análisis del discurso, hermenéuticos y semióticos, hasta investigaciones sociológicas y de carácter filosófico, se aproximan a la discursividad del movimiento con la intención de desentrañar sus elementos y explicar cómo la recepción política comienza a erigir formas organizativas en torno a una propuesta nacida desde la invisibilidad de los pueblos originarios levantados en armas.

Kathleen Bruhn (1999) realiza un análisis comparativo del discurso entre los posicionamientos políticos del EZLN y del EPR. Afirma que el zapatismo desarrolla la idea gramsciana de vincular a la sociedad civil con el movimiento revolucionario; selecciona alrededor de doscientos textos emitidos por los interlocutores de ambos movimientos, para localizar los conceptos usados con mayor frecuencia y, a partir de eso, interpreta las raíces ideológicas sobre las cuales se sustentan ambos movimientos armados. La diferencia discursiva radica en la jerarquización de los conceptos centrales de cada uno de los discursos, ya que eso explica, para el autor, cuáles propósitos persigue uno y otro grupo. Desde esta perspectiva, el EZLN inserta el uso del lenguaje como una estrategia de vinculación política con la sociedad civil, a diferencia del EPR que continúa con un trabajo revolucionario clásico, vanguardista y desvinculado de la base social.

El autor profundiza más en la relación de la práctica zapatista con la teori- 
zación de Gramsci y habla de las características discursivas de los comunicados del EZLN con una categorización, quizá elaborada por él mismo - no queda muy claro si la recoge de Le Bot-, e interpreta de manera muy superficial algunos comunicados. Hay continuas referencias a Laclau, sin embargo, no es evidente que el estudio se oriente hacia el análisis del discurso, puesto que su interés parte de la comparación léxica en el discurso de ambas guerrillas e introduce, al mismo tiempo, la comprobación de sus tesis acerca de la correspondencia entre el pensamiento de Gramsci respecto a la práctica del EZLN. Bruhn constata que entre la discursividad y la práctica política del movimiento zapatista existe una correspondencia ideológica que abre la posibilidad de pensar a los movimientos sociales como procesos dinámicos capaces de trascender, en el caso del EZLN, las reminiscencias del leninismo como la única posibilidad de hacer política desde la izquierda civil y armada. Un aporte significativo de este estudio es que trae al debate teórico lo que cultural y políticamente implica el uso del lenguaje para las bases de apoyo zapatista, en tanto que la palabra vincula el ejercicio político con la idiosincrasia de los pueblos mayas de México:

The "palabra verdadera" is, in addition, the key to Zapatista revolutionary strategy: a unifying consciousness and ultimately a wepon. The Word, like classs consciousness, espresses the identity of a social subject, though in the Zapatista lexicón, indigenoues (los indígenas) did not exist in a politcal sense; the Word "gave birth us" (Bruhn, 1999, p. 33).

La marginación de los pueblos originarios de la vida política nacional es también a través de las barreras culturales impuestas por el etnocentrismo, que ha tratado de castellanizar a las naciones indígenas como condición para su sobrevivencia. La resignificación simbólica del español en voz de los pobladores originarios, para declararle la guerra al estado mexicano y proclamar la palabra como la identidad común con los marginados de México y del mundo, tiene relación directa con la materialidad que guardan las palabras dentro de la cotidianidad de los pueblos. La palabra es verdadera porque es en sí una práctica significante, lo cual contrasta radicalmente con la cultura occidental. Javier Prado Galán (1997) utiliza la conceptualización hecha por Habermas y Apel, "ética discursiva", para afirmar que "la guerrilla sólo tiene sentido en su función de catalizadora del diálogo. Parece que éste ha sido el sentido y objetivo de la guerrilla zapatista." Soportando la premisa de cuán importante es la palabra como intervención política para el EZLN.

Marco Ambrosi (2018) confiere a la construcción de categorías lingüísticas y, por ende, simbólicas el carácter crítico del movimiento zapatista. La capacidad 
de resignificar "conceptos y términos clásicos" habla de un claro posicionamiento epistemológico de los pueblos originarios frente a la necesidad de ejercer teoría y praxis en un territorio determinado. Ambrosi habla de una "resistencia crítica" en la práctica zapatista, cuyos alcances interpretativos de la realidad inmediata y mundial son relevantes al intentar un acercamiento teórico del zapatismo. Quiere decir que la palabra como eje rector del pensamiento y del ejercicio político permite afirmar que existe una experiencia crítica al interior de los núcleos organizados, puesto que la construcción de entidades simbólicas ancladas en el lenguaje son herramientas de la transformación colectiva en términos simbólicos y materiales.

Una tesis inédita presentada en la UNAM en el 2012 (Hernández Gómez, 2012) desarrolla desde la filosofía política una explicación sobre la serie de símbolos entrañados detrás de la palabra zapatista. Relaciona de igual manera la ética discursiva con los procesos comunicativos que entabla el EZLN con la sociedad civil. Destaco de este trabajo el logro argumentativo de desentrañar el poder como el espacio en pugna que los zapatistas repudian y que además proponen deconstruir mediante el ejercicio colectivo de las bases. Lo anterior trasciende las erróneas interpretaciones hechas en torno al zapatismo sobre su renuncia a la lucha por el poder (Holloway, 2003), en tanto que rechazan al poder cimentado en estructuras verticales del Estado, pues, por el contrario, los comunicados exponen más bien alternativas colectivas para ejercer el poder "desde abajo":

La propuesta filosófica zapatista plantea la redefinición del poder, en una noción de la democracia enraizada en las prácticas culturales indígenas: hay nuevas definiciones de poder y democracia. Las comunidades indígenas se organizan por medio de asambleas, en las cuales se solucionan los conflictos y se regula la comunidad. Por medio del diálogo se plantean los problemas y sus soluciones. Los acuerdos que nacen en la asamblea son producto de un consenso y toda la comunidad se encarga de que se efectúen (Hernández Gómez, 2012, p. 167).

El autor destaca la estrategia discursiva como sustento de la propuesta política filosófica del zapatismo que, a su vez, encuentra algunas de sus raíces en la cosmovisión indígena maya:

En esta Segunda Declaraciónn de la Selva Lacandona, comienza a darse ese giro lingüístico de la guerrilla zapatista, tendiente hacia una expresión discursiva cercana al mito y a la alegoría, que utiliza un lenguaje menos convencional, fuera de las normas comunes del lenguaje político. Estas formas de expresión pretenden dar cuenta de la lengua que habla detrás de los pasamontañas, del mundo que subyace al levantamiento, 
que es el mundo cultural indígena (Hernández Gómez, 2012, p. 63).

Es decir que, también en este trabajo se localiza la importancia de la palabra como una praxis fundamentada en la filosofía zapatista, misma que produce una práctica colectiva fuera de toda tradición de las izquierdas. La "palabra verdadera" es resultado de una comprensión del mundo surgida en el territorio ancestral maya, pero que también trasciende los límites geográficos al increpar a la sociedad civil nacional e internacional, puesto que la organización se entiende como parte del sistema mundo inmerso en el sistema capitalista y, a partir de esa lectura, es que se piensa el trabajo político como una necesidad global para transformar verdaderamente las relaciones sociales:

El mandar obedeciendo del zapatismo tiene una significación profunda en tanto que nos enseña otra forma de concebir el trabajo político, las relaciones entre la sociedad y el gobierno, dota de valores éticos a la política y le hace entrar en la dialéctica fructífera de las relaciones simétricas entre gobernantes y gobernados (Hernández Gómez, 2012, p. 156).

Dos investigaciones publicadas del 2009 nuevamente acuden a la discursividad zapatista para recuperar elementos importantes para la discusión teórica. Los vínculos establecidos con diversos sectores sociales de todo el mundo, producto de la recepción de los comunicados zapatistas, sigue atrayendo la atención de los investigadores sociales. Nicolina Montesanano Montessori (2009) contrasta la discursividad del EZLN con la del presidente Ernesto Zedillo en un reducido período de tiempo, que va desde diciembre de 1994 a febrero de 1995; demuestra cómo ambos discursos utilizan estrategias de legitimización y deslegitimación, señalando el uso reiterado de nominaciones positivas y negativas para crear marcadas oposiciones entre los agentes de la disputa política en ese momento. Se reconocen las relaciones sintagmáticas que conectan los principales argumentos de ambos discursos para explicar que, lo que pareciera sostener la argumentación, se fundamenta en la construcción de narrativas de contraste. Es decir, la nominación propia y del otro hilan discursivamente la argumentación de los interlocutores en pugna, lo cual es rastreado por el autor mediante técnicas del análisis del discurso que explicitan cuál es la estructura gramatical en cada una de las intervenciones que emite el grupo rebelde y el presidente de la República.

Inherente a la "palabra verdadera" hay un ejercicio dialógico de los pueblos autónomos zapatistas, el cual denota la práctica ética de los principios del "mandar obedeciendo". Roberta Sigüenza y Karina Ponce (2018), al hablar del zapatismo como una "propuesta subalterna desde el sur", señalan: 
[las] nuevas formas de organización a partir del diálogo, la discusión y el debate crítico con su pueblo en asambleas, así se transforman las relaciones sociales de poder deslindándose de la influencia del sistema capitalista y de la reproducción de las situaciones coloniales en sus comunidades (p. 64).

La importancia que tiene para los pueblos originarios de América el uso del lenguaje como práctica de comunicación colectiva para la toma de decisiones y la construcción de consensos no es algo nuevo. Sin embargo, el cruce entre las prácticas de toma de decisiones colectivas por las comunidades mayenses de la zona chiapaneca y el novedoso ejercicio autonómico en las regiones zapatistas exige observar con mayor detenimiento cómo es que la palabra es un vehículo y herramienta de la construcción de esa otra forma de hacer política, que ha permitido al movimiento entrar en comunicación con diversos sectores de México y del mundo y, a la vez, consolidar el avance de su propia autonomía.

En "Construcción y movilización de la sociedad civil en el discurso del Ejercito Zapatista de Liberación Nacional (EZLN)" (Pavón Cuellar et al., 2009) los autores afirman que la Sociedad Civil es una configuración lingüística rastreable en la comunicación del movimiento zapatista y sus interlocutores:

La sociedad civil fue literalmente construida, no por los individuos que realizaron el trabajo discursivo, sino por las estructuras de los discursos que determinaron dicho trabajo, estructuras compuestas de posiciones y relaciones, estructuras supra-individuales indisociables de las estructuras sociales de las que forman parte (Pavón Cuellar et al., 2009, p. 324).

Es muy claro el análisis surgido desde este acercamiento metodológico, ya que vincula al texto con el contexto, cuyos matices históricos determinan una situación que, a su vez, incide en la construcción discursiva del elemento analizado: la sociedad civil. Los resultados muestran la configuración cada vez más afinada de la llamada sociedad civil en la discursividad del zapatismo, otorgándole una importancia fundamental para la interlocución del movimiento armado. Sin embargo, a pesar de evidenciar las relaciones sintagmáticas, con base en relaciones semánticas donde la adjetivación nominal es el núcleo constructor de ese actor, quizá no se termina de explicar, entonces, cuál es la importancia de esa sociedad civil o por qué la relación comunicativa establecida entre los rebeldes y los civiles representa un hecho inédito en la participación política de la sociedad mexicana. Es decir que, quien al nominar a la sociedad civil como su principal interlocutor es el EZLN, abriendo una forma distinta de irrupción de la 
participación ciudadana, la voz, tomada por la fuerza por el grupo armado, le es compartida a la anónima y heterogénea ciudadanía, cuya limitada participación política resulta arengada por los rebeldes que la configuran y la interpelan.

Los análisis discursivos vinculan los usos del lenguaje con el contexto sociopolítico en que son producidos, razón por la cual aportan significativas conclusiones acerca de los hablantes y el impacto social que tienen los comunicados de ciertos sectores sociales. Una tesis inédita de 2011 (Díaz García, 2011) explora ampliamente la relación que guardan los comunicados del EZLN y su potencia simbólica con el contexto histórico nacional y las condiciones económico culturales que enmarcan el levantamiento armado. Este trabajo ilustra desde los estudios críticos del discurso la materialización de la lengua en procesos sociales que, además, dan cuenta de cómo los productores de dichas comunicaciones ven en la lengua una herramienta para la lucha política en el escenario nacional e internacional:

La crítica a una determinada manera de pensar el cambio social necesariamente se expresa en un nuevo lenguaje, en conceptos y categorías que permiten o intentan dar un nuevo contenido a las palabras mediante las cuales pensamos ese cambio. Las notas que hemos expuesto en este trabajo han tenido como objetivo mostrar un conjunto de palabras, nociones y conceptos, elaborados en distintos escenarios, pero que creemos forman lenguajes de una constelación que está marcada por la crisis del sujeto clásico de la revolución y la emergencia de una nueva manera de pensar la lucha de clases (Tischler, 2014).

Sin embargo, a pesar de la relevancia que se puede adjudicar a la forma en que la discursividad refleja los procesos de transformación política al interior de la organización y cómo expresa una visión determinada frente al quehacer político, en oposición al estado de cosas materializado en el sistema capitalista neoliberal, autores como Sabrina Melenotte (2015) cuestiona qué tanto los estudios sobre el zapatismo se han basado únicamente en la discursividad sin corroborar cuál es el sustento material de la autonomía y la implementación de los mecanismos de la democracia directa: "their works always start from the political discourse of the organization and from the postulate that consensus and horizontality are a fairer way to make politics" (p. 54). Siguiendo a la autora, es cierto que las investigaciones atraídas por una discursividad novedosa en la práctica revolucionaria, poniendo en jaque el mismo concepto de Revolución practicado por los movimientos vanguardistas, deben profundizar en los procesos que moldean esos usos del lenguaje. 
John Holloway (2002) habla de la influencia que el EZLN ha ejercido en el desarrollo de las ciencias sociales que se precian de ser críticas, precisamente por la resignificación conceptual llevada a cabo por el movimiento:

Revolution, even emancipation, become ridiculous words. Well, of course: we are getting old. But that is not the problem. The problem is that the young too are old, many of them, sometimes even older than the old. The problem is that the world is getting old (Holloway, 2002, p. 154).

El zapatismo, continúa Holloway, cuestiona la manera en que se está (mal) entendiendo la realidad social desde la academia sin el propósito de transformar el estado de cosas que están orillando al planeta hacia la destrucción:

Expectations are scaled down. The bitterness of history teaches us that it is now ridiculous to maintain the grand narrative of human emancipation, the grand narrative of hope for a society based on human dignity. [...] The conditions of academic life, the need to finish theses, the need to get jobs, the pressure to get grants: all push in the same direction. Everything tells us to focus on our own specialised fragment of knowledge, to forget the complexity of the world (p. 154).

Razón por la cual la resignficación discursiva lograda por el zapatismo, no sólo es una propuesta que rompe con paradigmas de lucha en el espectro de las izquierdas, sino que también abre posibilidades de comprender e incidir en la realidad que cimbran los círculos académicos. Es decir, la práctica política del movimiento, reflejada en una nueva discursividad, se ha convertido en un referente obligado de las luchas antisistémicas:

Un actor muy relevante para el autonomismo, y el movimiento en general, ha sido el zapatismo. El levantamiento de enero de 1994 en Chiapas contra la firma del Tratado de Libre Comercio de América del Norte (TLCAN, o NAFTA por sus siglas en inglés) fue crucial para la evolución del MAG. En el seno de los Encuentros Intergalácticos Contra el Neoliberalismo y por la Humanidad promovidos por el Ejército Zapatista de Liberación Nacional (EZLN) nació la Acción Global de los Pueblos (AGP), coordinadora de acciones de protesta globales (Ozerin, 2014, p. 75).

Por lo que continúa siendo imprescindible acudir a la experiencia del movimiento zapatista para entender los pasos organizativos que siguen dando hacia la construcción de alternativas a las relaciones sociales impuestas por el capitalismo de manera global e indiscriminada. La forma de comunicación, a pesar de ser una nueva manera paradigmática de establecer relaciones con la sociedad civil y 
promover la organización en los centros urbanos, es solamente la vía para acceder al complejo pensamiento zapatista $\mathrm{y}$, a partir de ahí, comprender la práctica de las comunidades levantadas en armas que en lo cotidiano fortalecen procesos autonómicos.

\section{LA MATERIALIDAD DE LA PALABRA, EL TERRITORIO}

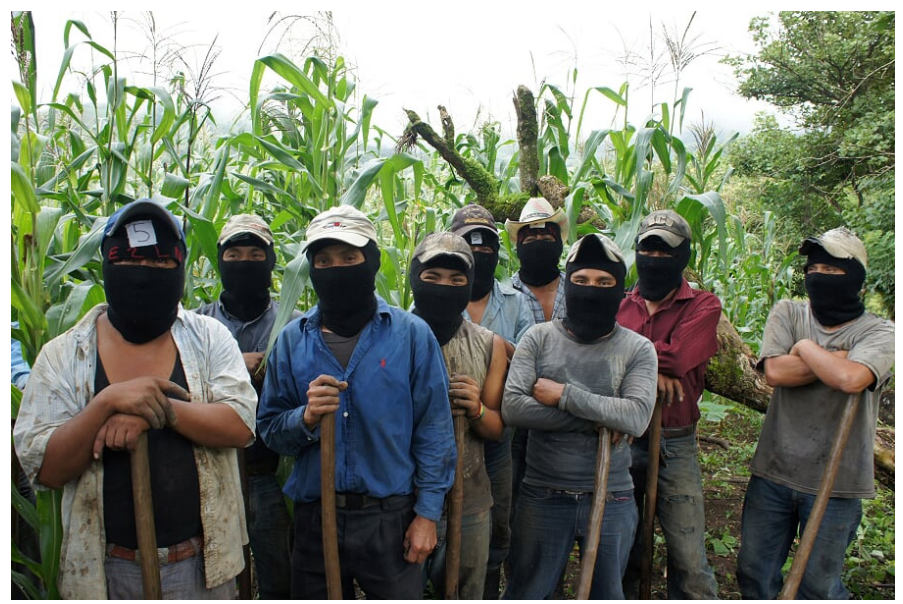

Escuelita Zapatista "La Libertad según l@s zapatistas". Fotografia de la autora.

Los análisis críticos del discurso explican la materialidad de la palabra en la serie de relaciones sociales que gestan los usos del lenguaje y desvelan los mecanismos en que las lenguas son utilizadas como herramientas del poder para el control simbólico de las subjetividades. Al hablar, entonces, de los usos del lenguaje, desde estos puntos de vista, no existe una desmaterialización de la lengua, sino que, con base en las condiciones históricas, se explica la posición que la lengua como sistema simbólico tiene al interior de los grupos sociales. Es decir, detrás de la discursividad pública del movimiento zapatista existe una serie de procesos materiales que sustentan ese entramado conceptual y dan cuenta de las relaciones sociales alternativas, que se desarrollan como propuesta política en 
contra de un estado de cosas capitalista. Para los pueblos mayas levantados en armas en 1994 el centro de la pugna y el motivo de la organización es la recuperación de la tierra para mantener relaciones económicas no capitalistas, porque es en el paradigma de la tenencia de la tierra en torno al cual se articulan las resistencias discursivas con las cuales establecen comunicación al exterior con la sociedad civil.

La territorialidad se sitúa en el centro de la lucha que se gesta no sólo mediante la discursividad, sino también en términos materiales. Qué sustento material más importante para la palabra del movimiento zapatista que el territorio y su conceptualización antropológica, como esa serie de relaciones histórico-sociales entramadas de manera simbólica en un espacio determinado, para encontrar en la palabra de los sublevados objetivos que persiguen la sobrevivencia de la tierra y la cultura. Marcos Daniel Silva Maldonado (2017) aborda la defensa territorial que enfrentan las comunidades zapatistas en contra del despojo sistemático; explica cómo la tenencia de la tierra guarda visiones de mundo en las cuales la comprensión del territorio radica en polos opuestos: "El espacio-tiempo indígena es distinto del que conforma el capitalismo, pues mientras el primero sacraliza la tierra y sus recursos naturales, el segundo cosifica y vuelve una mercancía a la tierra" (Silva Maldonado, 2017, p. 68). Los pueblos originarios establecen relaciones equilibradas con la tierra y sus recursos, mismas que trascienden las ideas contemporáneas del ecologismo:

No podemos afirmar que los pueblos indígenas no son ecologistas por antonomasia, pero sí podemos decir que los pueblos originarios han sabido adaptar su hábitat de manera muy singular, para lo cual han desarrollado un conjunto de elementos tecnológicos ad hoc al medio ambiente (Silva Maldonado, 2017, p. 72).

En un análisis muy breve, el autor contrasta las ideas sobre la propiedad de la tierra que entran en una fuerte disputa con la resistencia zapatista. En contra del despojo impuesto por la serie de reformas estructurales que sustentan el sistema de acumulación, el EZLN reivindica el territorio como un espacio donde se libran también batallas de carácter simbólico, pues es la idea de mundo de los pueblos originarios la que trata de sobrevivir frente a la lógica de acumulación por despojo capitalista. La tierra no es sólo una propiedad, sino que es un lugar con significados que generan identidad y también engendran resistencia, motivo por el cual la discursividad necesariamente es una herramienta de lucha en el terreno simbólico, pero, en el caso del zapatismo y de los pueblos originarios, también en lo material, que se articula en torno a la configuración del imaginario 
territorial por el cual se resiste:

La defensa de la territorialidad implica que hay un modo diverso de ver al mundo distinto del que comanda el modelo hegemónico. El EZLN busca la vindicación del sujeto indígena bajo un constructivismo encumbrado como movimiento sui generis que se conforma de "abajo hacia arriba" (Silva Maldonado, 2017, p. 73).

La nominación territorial del zapatismo no tiene una menor relevancia, en el sentido de que muestra cómo es pensado el sistema mundo y las territorialidades al interior del capitalismo, lo cual puede interpretarse como la vía que toma el movimiento para explicarse la configuración del espacio inserto en la lógica acumulativa, para fortalecer e impulsar la resistencia contra el despojo. Álvaro Reyes en su artículo "Zapatismo: other geographies circa 'the end of the world'"(2015) profundiza en la reforma al artículo $27^{\circ}$ como el principal punto de inflexión que empujó al EZLN a declarar la guerra contra el Estado mexicano; afirma que las modificaciones a las leyes agrarias lo que estaban anunciando era el reordenamiento territorial capitalista respaldado por la clase política nacional:

Habría que recalcar entonces que cuando los tres grandes partidos políticos fulminaron la iniciativa del EZLN de reavivar el Artículo 27 a través de las Reformas Constitucionales en materia de Derechos y Cultura Indígena, su actuación no respondía únicamente al deseo de la clase política mexicana de excluir a los pueblos indígenas de México del "pueblo mexicano" (aunque este deseo sin duda se hizo presente). Respondía también a una situación mucho más novedosa donde la clase política mexicana, a través de su completo abandono del ordenamiento territorial implícito en el Artículo 27, quería ahora admitir abiertamente que la descomposición del Estado mediador postrevolucionario era de hecho irreversible (Reyes, 2015, p. 6).

La disputa por el territorio originario implica, entonces, una disputa que rebasa las fronteras nacionales, debido a que sitúa la confrontación discursiva en torno a las relaciones paradigmáticas de la humanidad con el espacio que habita. De ahí que la palabra zapatista, por muy sencilla que pareciera, impreca una visión de mundo que amenaza la forma de vida de los pueblos originarios. La visión capitalista de mundo impone vínculos con el espacio abstraídos de la realidad histórica del territorio y sus habitantes. Reyes cree que es decisiva la reforma al $27^{\circ}$ constitucional para que los procesos de despojo en el campo y la ciudad pudieran ejercerse, ya que el reordenamiento territorial no es únicamente la toma de tierras para uso productivo, sino el control simbólico de los espacios comunes y la desarticulación de las redes comunitarias cuya identidad se arraiga 
al espacio físico.

Reyes habla en términos de geometría política para establecer una conceptualización de lo que el zapatismo denomina como nuevas geografías y que dan cuenta del reordenamiento planetario, producto de las constantes guerras de despojo en contra de la población originaria. Es evidente que, detrás del reordenamiento, existen procesos de descomposición social que facilitan la entrada a los territorios y la erosión de las identidades que pudieran impulsar movimientos de resistencia en defensa de la tierra: "En este punto, pues, los zapatistas son capaces de añadir coordenadas a nuestra "geometría política" contemporánea: existe el mundo dominante de la valorización capitalista "allá arriba, pero existen al mismo tiempo muchos mundos, inmanentes al primero, aquí abajo." (Reyes, 2015) Propone, además, que "tales valoraciones dualistas deben complejizarse aún más: todo debe analizarse en función de una rejilla cuadrangular compuesta a un mismo tiempo de izquierda/derecha y arriba/abajo" (Reyes, 2015).

Con el acercamiento de Reyes, se abre la posibilidad de dimensionar la discursividad zapatista, tocante a la nueva geografía, como una forma nueva de entender no sólo el reordenamiento territorial que el capitalismo lleva a cabo mediante mecanismos de guerra, sino también para poder profundizar en cómo desde "los abajos" se gestan relaciones sociales, que no sólo reniegan de la temporalidad acumulativa, sino que también construyen otras vías para entender y vivir el mundo-territorio en el cual habitan. Sergio Rodríguez Lascano (2017) escribe:

La respuesta de los pueblos zapatistas es la creación de nuevas relaciones sociales en sus territorios, que tiene que ver no sólo con lo que llamaríamos las relaciones de producción, sino también con todos los mecanismos para poder construir una democracia desde abajo (pp. 50-51).

En el sur-abajo de la geometría global hay relaciones que se pueden llamar de resistencia, no sólo productivas, mismas que se transforman continuamente y que representan la base material de los procesos sociales de renovación. La correspondencia entre la discursividad zapatista con la práctica cotidiana, que refleje ese tipo de relaciones que trascienden la temporalidad y el espacio como el capitalismo lo entiende y lo impone, debe ser punto de partida para el estudio profundo y detallado de esas alternativas de vida colectiva frente a la crisis civilizatoria de la actualidad:

Esta nueva forma y praxis radical de otra democracia y una nueva ética del imaginario social, se fundamenta en la transformación y cambio 
de cómo repensar el poder, la ética y la política en la que, claramente, no exista un dominio o subordinación en el ejercicio de una función o cargo público, por el contrario, esta deberá ser concebida como una responsabilidad ética, solidaria y comprometida por el bien común (Fuentes, 2017, p. 85).

Fuentes explica que las relaciones productivas al interior de las comunidades autónomas coexisten con la lógica acumulativa del mercado en que está inserta la geografía de las bases de apoyo zapatistas. Es claro también para el zapatismo que, por esa razón y, entendiendo la totalidad como el sistema mundo, existe la necesidad de globalizar los procesos de resistencia contra las formas de dominación capitalistas. Sin embargo, tampoco se puede negar que la resignificación del territorio, a través del cambio en las formas en que el espacio es entendido por sus habitantes abre múltiples posibilidades para que esos tipos de resistencia en todo el mundo se conviertan en las posibles vías de acceso hacia la construcción de "otros mundos", cuya posibilidad se hace patente frente a la diagnosticada crisis del sistema capitalista.

\section{OTRA ECONOMÍA}

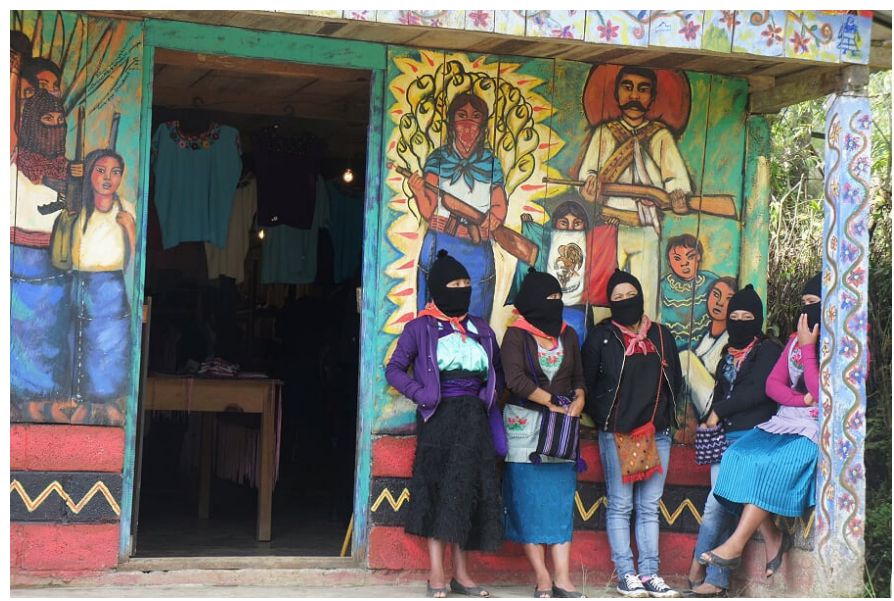

Tienda-cooperativa textil de mujeres (Oventik - 2/05/15). Fotografia de la autora. 
El levantamiento armado, como condición necesaria para la recuperación de tierras, permitió a la organización ejercer su derecho al autogobierno y la construcción de la autonomía. Con el territorio guardan una relación no mercantil y es sobre el espacio físico donde se construyen las relaciones simbólicas fuera de la fetichización de la mercancía. Bien rescata Leandro Vergara-Camus las aportaciones del etnólogo Carlos Lenkersdorf para profundizar en el significado que tiene la tierra para los pueblos mayas tojolabales. Ya André Aubry había desarrollado un concepto de territorio con base en los profundos vínculos que los pueblos tzotziles establecen con la tierra como la madre. En el artículo de Vergara-Camus (2016), "Tomando el control: autonomía, subsistencia y desmercantilización. Gérmenes de otra economía en las luchas de los zapatistas en Chiapas y los sin tierra en Brasil", se afirma que, sin el control territorial de ambos movimientos, la puesta en práctica de proyectos de autogestión sería menos posible.

Con un aparato conceptual marxista, Vergara-Camus aborda la descripción de las economías emergentes de los dos movimientos y cuestiona la incapacidad que ambos tienen para llevar a cabo una transformación de las relaciones de producción más allá de los territorios que han sido "tomados" "ocupados" o "recuperados" en ambas experiencias político-organizativas: "El EZLN y el MST, por sí solos, no tienen la capacidad de ir transformando las relaciones sociales de reproducción y producción más allá de los espacios controlados por ellos" (p. 130). Sin embargo, aunque explica detalladamente las estrategias económicas que los movimientos, para él análogos, han tomado para sobrevivir y resistir, cuyas características escapan a la lógica mercantil del neoliberalismo, también cuestiona que existe una dependencia del mercado para el intercambio comercial. Es cierto que los bienes producidos por las diversas cooperativas y proyectos productivos zapatistas se intercambian al interior de las zonas autónomas o se venden al exterior, mediante los vínculos con colectivos solidarios, pero la socialización de los medios de producción y la revalorización del tiempo (trabajo) son elementos que es necesario discutir y profundizar.

La comparación llevada a cabo por el autor permite poner de relieve las fuertes disonancias entre ambas experiencias. Por un lado, la relación con el Estado es clave para entender los límites de lo que los zapatistas han llamado "la autonomía legal" frente al ejercicio de la "autonomía real". En el libro El pensamiento Crítico Frente a la Hidra Capitalista (EZLN, 2015), en voz de los y las zapatistas se describe cómo ha evolucionado la "otra" economía. El EZLN explica cómo, con base a la independencia económica no sólo en relación al Estado sino, también y muy importante, frente al apoyo, a veces solidario, a veces no, de organi- 
zaciones no gubernamentales, asociaciones civiles internacionales y nacionales, así como a colectivos e individuos afines; es que se ha consolidado el desarrollo autónomo de los caracoles, zonas y regiones controlados por el movimiento. El MTS, por su parte, mantiene una relación con el Estado de exigencia y negociación, lo cual los ha supeditado a que les sean concesionados ciertos beneficios económicos que han permitido la subsistencia de las familias. El autor menciona cómo en los procesos de acampadas "se presionaba a las autoridades municipales para obtener una cesta básica por familia acampada” (Vergara-Camus, 2016, p. 134). Lo cual, en realidad, distancia por completo ambas experiencias, dado que, sin independencia económica, autogestiva, resulta difícil decir que existe un intento de economía "otra", anticapitalista, o solidaria, para ambos casos.

\section{RECAPITULAR}

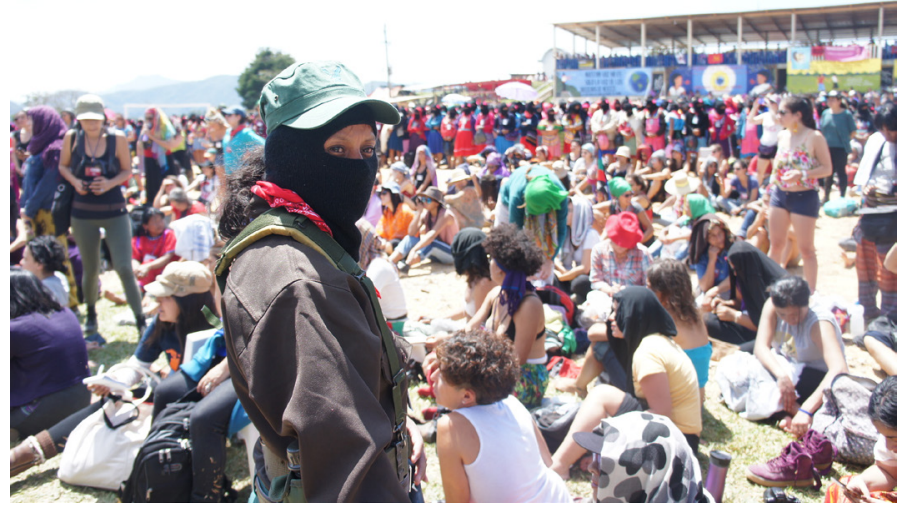

Primer encuentro internacional, político, artístico, deportivo y cultural de mujeres que luchan (8/03/18). Fotografia de la autora.

La vinculación de la discursividad con la cuestión territorial obedece a la importancia de materializar la lengua en sus procesos sociales de producción y, sobre todo, focalizar en la palabra zapatista la praxis intrínseca tal y como la en- 
tienden los pueblos originarios. Hablar de territorio es localizar geográficamente las pugnas políticas que se gestan en torno, y por, un espacio físico concreto que, además, no es únicamente un lugar delimitado en una relación de propiedad. Para los pueblos originarios y campesinos, el territorio guarda significados que le otorgan identidad al grupo social que lo habita, cuya relación escapa a las formas "válidas" que el sistema de producción promueve sobre la tenencia de la tierra. En ese sentido, es la territorialidad la condensación de los discursos, en tanto que se expresa en el lenguaje simbólico la lucha que desde "abajo" se libra contra el imaginario impuesto sobre la tierra y las personas.

La lengua ha sido el puente que investigadores han transitado para tratar de llegar hasta el extremo donde el pensamiento zapatista se construye de manera práctica, también como una característica de la organización que equilibra teoría y praxis, ya que no fragmenta la realidad para comprenderla ni para intentar transformarla. Es por ello que la búsqueda de las relaciones sociales cuya construcción permanente "llena" la temporalidad (Tischler, 2014) resulta trascendente para comprobar las posibilidades que existen de que el capitalismo en su lógica acumulativa sea trascendido por este tipo de experiencias organizativas. Si "el sistema-mundo moderno en el que vivimos no puede continuar porque se ha alejado demasiado del punto de equilibrio y a los capitalistas ya no les posible acumular capital de manera ilimitada" (Wallerstein, 2015, p. 45). Entonces, focalizar la atención en las geografías que, aunque insertas en el sistema global, combaten la dominación en todas sus formas dará respuestas sobre cómo desde "los abajos" emanan las alternativas para sobrevivir a la catástrofe civilizatoria que actualmente padece el mundo como consecuencia del propio sistema. Lo más lógico tal vez sería comenzar a hablar del inminente colapso planetario, como consecuencia irreversible que los procesos productivos capitalistas ha provocado.

La intención es profundizar en cómo en los últimos cinco años de práctica de la autonomía el zapatismo configura en su zona de influencia relaciones sociales que combaten la dominación; de esa manera también es que se puede hablar de las "otras geografías", cuya nominación se pretende tomar de la discursividad que los propios pueblos y sus voceros han ofrecido para compartir la forma en que explican la realidad y sus trasformaciones. Es encontrar en la palabra su sustento territorial para desarrollar explicaciones que dieran cuenta de cómo es que esa geografía alberga otro tipo de relaciones y cuáles son los elementos que sustentan la afirmación de una trascendencia al estado de cosas capitalista. Para lograr ese acercamiento, resulta primordial partir de las teorizaciones que sobre el zapatismo existen, pero también de la palabra del movimiento que se ha ex- 
plicado a sí mismo y, en los últimos años, también ha transmitido su experiencia organizativa con organizaciones e individuos de todo el mundo en la Escuelita zapatista.

Otra de las intenciones de este trabajo es poder describir a mayor profundidad el cambio en las relaciones económicas al interior de las comunidades controladas por el EZLN, de qué manera se lleva a cabo el comercio al interior y exterior de sus productos y cuál es el uso real que le dan al dinero. La construcción de la autonomía y esa otra economía es fundamental para conocer la transformación en las relaciones sociales, pese a que el capitalismo como sistema dominante siga existiendo y tratando de absorber todas las formas de vida no adecuadas para su acumulación. La complejidad de las relaciones es aquello que se intentará desentrañar, puesto que es ahí donde radican análogamente las relaciones de dominación capitalistas y patriarcales. No es sólo un intento por explicar desde la materialidad una complejización de lo simbólico, sino cómo la relación es recíproca y cómo los factores económicos son importantes más no determinantes del todo para poder afirmar que la transformación se ha llevado a cabo también en esferas que las anteriores experiencias de lucha no habían contemplado o habían desdeñado.

Los previos acercamientos en sus variantes disciplinarias no responden aún en su totalidad a la búsqueda sucedánea de querer comprender cómo un movimiento armado, de cuyo seno y como consecuencia nace un proceso autonómico, responde de formas prácticas a la guerra que contra ellos se ha ejercido desde las diversas esferas de los poderes locales y nacionales. Su diagnóstico sobre el actual momento que vive el capitalismo debe retomarse por la elocuencia con que han descrito en los recientes años los procesos que la realidad se ha encargado de comprobar. El interés por el EZLN es vasto y por ello las investigaciones son múltiples y diversas. Sin embargo, es necesario llevar a cabo una actualización de lo que se ha escrito sobre el movimiento, mas con herramientas teóricas que partan de la Ciencia Política para encontrar elementos que hayan escapado a otros acercamientos.

\section{REFERÊNCIAS}

Ambrosi, de la Cadena Marco. "El Zapatismo como 'resistencia crítica’al neoliberalismo". Ecuador: Chakiñan, Revista de Ciencias Sociales y Humanidades (4), 28-42, 2018. 
Bruhn, Kathleen. "Antonio Gramsci and the Palabra Verdadera: The Political Discourse of Mexico's Guerrilla Forces". Inglaterra: Journal of Interamerican Studies \& World Affairs, 41, 29-55, 1999.

Díaz García, Reyna Livia. (2011). La Comunicación, discurso e ideología: el discurso político del Ejército Zapatista de Liberación Nacional (EZLN), 1994-1998. (Licenciatura en Ciencias de la Comunicación Inedit) (001-00424-D5-2011). México: Universidad Autónoma de México, 2011.

Ezln, Comisión Sexta. El Pensamiento Crítico Frente a la Hidra Capitalista (Vol. I). México: Comisión sexta EZLN, 2015.

Fuentes Sosa, Samuel. "Crisis civilizatoria y la construcción descolonizadora del saber desde el "mandar obedeciendo": la actualidad de Mariátegui". Venezuela: Utopía y Praxis Latinoamericana, 22 (77), 77-88, 2017.

Hernández Gómez, Alfonso. La palabra del EZLN: voz de la liberación: la filosofía política zapatista y los pueblos indígenas de Chiapas. (Licenciatura en Filosofía inedita) México: Universidad Nacional Autónoma de México, 2012.

Holloway, John. "Zapatismo and the Social Sciences". USA: Capital \& Class, 26, p153-160, 2002.

Holloway, John. Cambiar el mundo sin tomar el poder. Buenos Aires: Herramienta, 2003.

Melenotte, Sabrina. "Zapatista autonomy and the making of alter-native politics: Views from its day-to-day praxis”. USA: Focaal, (72), 51-63, 2015.

Montesano Montessori, Nicolina. "Contrastive analysis of the preferred and unpreferred readings in political discourse in mexico: The contestations of presidential texts by the zapatista army of national liberation (ezln)". España: Oralia, 12, 219-245, 2009.

Ozerin, Iratxe Perea. "El papel del feminismo en el movimiento antiglobalización: contribuciones y desafíos/The role of feminism in the antiglobalization movement: contributions and challenges". Barcelona: Revista CIDOB d'afers internacionals, 67-88, 2014.

Pavón Cuellar, David; Sabucedo, José Manuel; Alzate, Mónica \& López, Wilson. "Construcción y movilización de la sociedad civil en el discurso del Ejercito Zapatista de Liberación Nacional (EZLN)". Colombia: Revista Latinoamericana de Psicología, 41, 323-334, 2009.

Prado Galán, Javier. "La etica discursiva: Una etica para la democracia". México: Xipe Totek, 6, 152-154, 1997.

Reyes, Álvaro. "Zapatismo: other geographies circa "the end of the world”'. USA: 
Environment and Planning D: Society and Space, 33(3), 408-424, 2015.

Rodríguez Lascano, Sergio. "Visión zapatista sobre la tormenta que está sobre nosotros". México: Observatorio del Desarrollo, 6, 44-51, 2017.

Sigüenza, Roberta; Ponce, Karina. “ ¿Es posible romper con el capitalismo desarrollista? Dos propuestas subalternas desde el Sur”. Ecuador: Huella económica, Vol. 3 (1), 57-66, 2018.

Silva Maldonado, Marcos Daniel. "La defensa de la territorialidad por parte del ezln, ante el desarrollo socioambiental capitalista”. México: El Cotidiano (201), 2017.

Tischler, Sergio. "El muro, las grietas y la idea de revolución y destotalización." Paper presented at the Seminario El pensamiento crítico frente a la hidra capitalista, CIDECI, Unitierra, San Cristóbal de Las Casas, Chiapas, México, 2014.

Vergara-Camus, Leandro. "Tomando el control: autonomía, subsistencia y desmercantilización. Gérmenes de otra economía en las luchas de los zapatistas en Chiapas y los sin tierra en Brasil." In J. L. Coraggio (Ed.), Economía social y solidaria en movimiento (pp. 129-142 ). Buenos Aires: Universidad Nacional de General Sarmiento, 2016.

Wallerstein, Immanuel. "La crisis estructural, o por qué los capitalistas ya no encuentran gratificante al capitalismo" (B. R. d. l. Concha, Trans.). In Wallerstein, Immanuel, ¿Tiene futuro el capitalismo? (pp. 15-46). México: siglo xxi editores, 2015 .

\section{OUTRAS GEOGRAFIAS, MUITOS MUNDOS. UMA ABORDAGEM DA LUTA ZAPATISTA E DA CONFIGURAÇÃO DAS RELAÇÕES SOCIAIS ANTICAPITALISTAS}

\footnotetext{
Resumo: Este trabalho faz parte de um projeto de pesquisa em andamento; pretende apontar, a partir das várias disciplinas que foram dirigidas a zapatismo, no que elementos reside a peculiaridade desta experiência política que a diferencia de outras formas de luta antisistémica. O texto é baseado em uma breve contextualização da revolta armada zapatista em 1994, bem como uma breve conceituação de lutas antissistêmicas ou anticapitalistas. Posteriormente, esta análise tenta descrever como o aterramento e a resistência permanente por e no território representam a materialidade que deu vida à imponente discursividade zapatista. Para
} 
este fim, este artigo faz um estado da arte da pesquisa precedente que, focalizada em zapatismo, endereçar das várias disciplinas os conceitos que este trabalho tenta cruzar na aproximação à experiência de Zapatista; esses conceitos seriam: discurso, autonomia, resistência e território.

Palavras-chave: Zapatismo. Autonomia. Lutas anticapitalistas. Território. Povos indígenas

\title{
OTHER GEOGRAPHIES, MANY WORLDS. AN APPROACH TO THE ZAPATISTA STRUGGLE AND THE CONFIGURATION OF ANTI- CAPITALIST SOCIAL RELATIONS
}

\begin{abstract}
This work is part of an ongoing investigation's project; it's triyng to mark, from diferents disciplinary views that zapatism has been studied, what are the more relevant elements or reasons why zapatist experience is completly particular and diferent in front of anothers ways to struggle against system. The text starts with a short summary about the social and politic context in wich the zapatists appear in 1994, in addition, there is a brief discussion about how "Anti-capitalism", like concept, was born and become in an important way to resist to capitalist system by many movements and people around the world. This essay pretends describe the material side of zapatist speech; from this particular view, the land represents the match point between material and symbolic strugle that zapatist have been developed during twenty yers. The main concepts that are present in the diferents research works are: Speech, Autonomy, Resistence and Territory.
\end{abstract}

Keywords: Zapatism. Autonomy. Anti-capitalism struggles. Territory. Indigenous peoples. 